\title{
COMUNICAÇÃO
}

\section{ASPECTO HISTOLÓGICO INCOMUM EM CASO DE FEBRE AMARELA OCORRIDO NO GRUPO INDÍGENA YANOMAMI}

\author{
Vera Lúcia R. Barros, Mário A. P. Moraes, Gilberta Bensabath e Maria Aparecida Silva
}

Em novembro de 1991, três crianças Yanomami adoeceram, a intervalos de alguns dias, na aldeia Alto Catrimâni, Estado de Roraima, com manifestaçõess de uma hepatite grave: febre, vômitos, icterícia e sangramentos. Elas faziam parte de um grupo de indígenas que se deslocara para o local, algum tempo antes, caminhando através da mata, como é de hábito entre os Yanomami. Removidas da área, duas das crianças faleceram em Boa Vista, RR, e a outra, em Manaus, AM, fato que permitiu a obtencão de amostras hepáticas, por viscerotomia. A primeira criança a falecer, no dia 17 de novembro, uma menina de 4 anos, apresentava no fígado, micróscopicamente, alteracões degenerativas intensas, com numerosas células em "mórula" ou em “aranha” - aspecto sugestivo, à primeira vista,

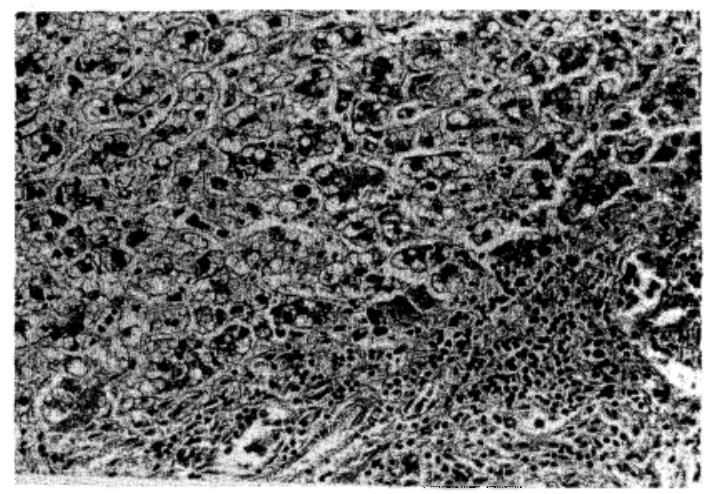

Figura 1 - Fígado. Numerosas células em degeneraçāo gorda multivacuolar (células em "mórula"), na zona média do lóbulo. Notar, no centro da foto, um corpúsculo de Councilman. $200 x$.

do quadro típico da hepatite de Lábrea (delta). Nos dias $18 \mathrm{e} 21$ de novembro morreram as outras duas; ambas do sexo masculino, de oito e quatro anos, respectivamente. Do sangue retirado da última,

Instituto Evandro Chagas, Fundação Nacional de Saúde/ Ministério da Saúde, Belém, PA, Faculdade de Ciências da Saúde, Universidade de Brasília, Brasîlia, DF e Fundação Nacional do Índio, Boa Vista, RR.

Endereço para correpondência: Dr. Mário A. P. Moraes. FS/ PTL/UnB, CP: 15-3031, 70910-970 Brasília, DF.

Recebido para publicação em 02/06/92.

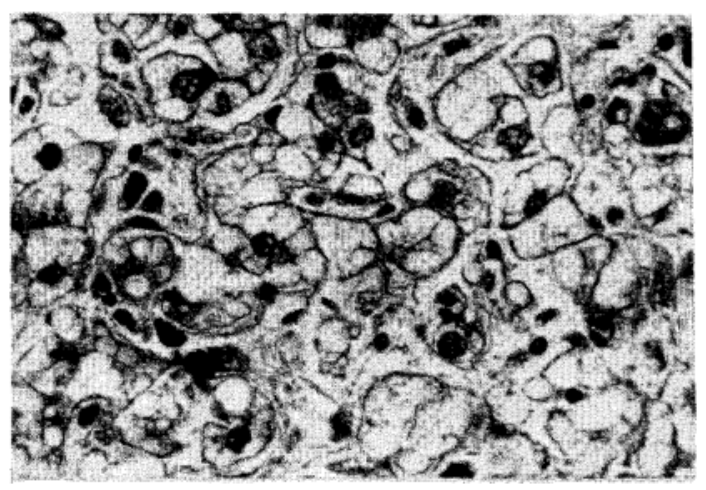

Figura 2 - Fígado. Típicas células em "mórula". 500x.

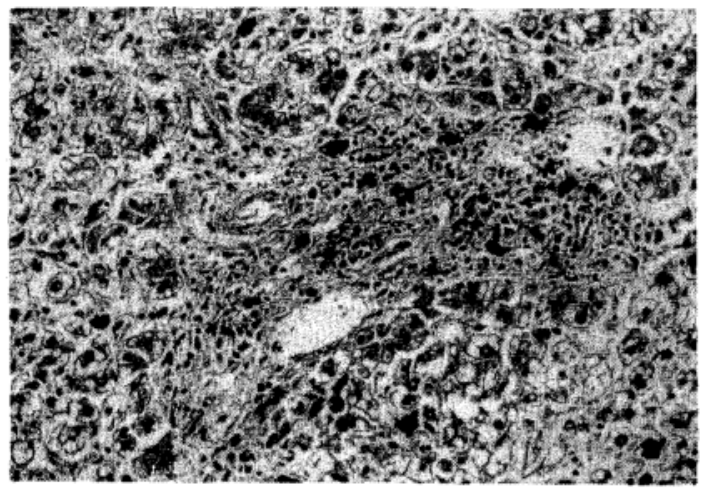

Figura 3 - Figado. Área portal com pigmento malárico infiltrado de células mononucleadas. Os hepatócitos, em torno dessa área, ainda nãoforam totalmene atingidos pela esteatose. $200 x$.

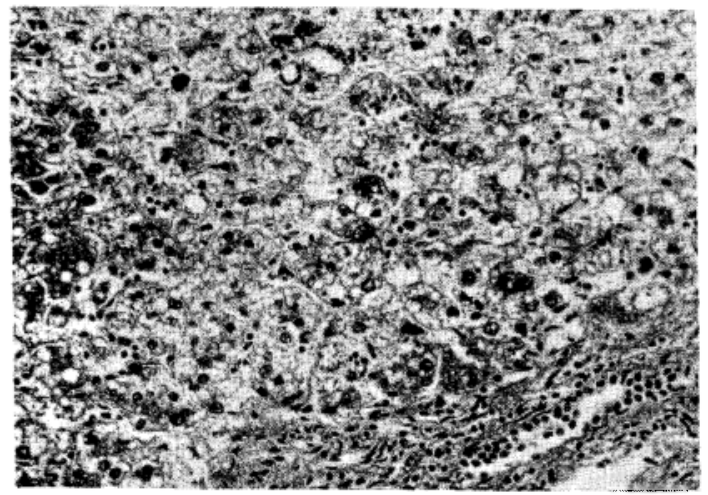

Figura 4 - Fígado. Células com antígeno do virus da febre amarela demonstrado pela fosfatase alcalina. Observarna parte superior, à èsquerda, um corpúsculo de Councilman também corado. $200 x$. 
Comunicação. Barros VLR, Moraes MAP, Bensabath G, Silva MA. Aspecto histológico incomum em caso de febre amarela ocorrido no grupo indigena Yanomami. Revista da Sociedade Brasileira de Medicina Tropical. 25:279-280, out-dez, 1992.

ainda em vida, isolou-se, no Instituto Evandro Chagas, em Belém, PA, o vírus da febre amarela. A histopatologia do fígado, nestes dois casos, não deixou qualquer dúvida sobre a natureza amarílica das lesões: era evidente a localização mediozonal (lesão de Rocha Lima) da chamada necrose lítica e dos numerosos corpúsculos eosinofílicos (corpúsculos de Councilman) formados pela necrose hialina dos hepatócitos.

Logo após as três mortes, vinte indígenas (doze adultos e oito crianças), participantes do mesmo grupo, forneceram soros para o teste da detecção de anticorpos da classe IgM (MAC ELISA) contra o vírus da febre amarela. Houve positividade em quatro, sendo um deles o soro da mãe da menina primeiro falecida. $O$ mesmo teste foi negativo com o soro do menino do qual se isolara o vírus.

Os dados acima mostram que um surto de febre amarela silvestre ocorreu, realmente, entre os índios do grupo recém-chegado ao Alto Catrimâni. Além disso, pela imuno-histoquimica, foi possivel demonstrar-se nos fígados das três crianças mortas a presença de antígeno do vírus da febre amarela. Assinale-se, incidentalmente, que em todos havia também pigmento malárico nas áreas portais e, em menor quantidade, nos lóbulos hepáticos, dentro de algumas células de Kupffer. A disposição do pigmento indicava um ataque anterior de malária nos meses que precederam a infecção pelo vírus da febre amarela.

A presente comunicação tem a ver principalmente com o caso da criança que apresentava no fígado as células em "mórula". Conquanto, se tivesse detectado a presença de antígeno amarílico em células do parênquima, o quadro histológico podia fazer supor uma infecção pelo vírus delta ${ }^{1}$. Para confundir ainda mais o diagnóstico, verificouse, em 69 indígenas da área, cujos soros foram testados para marcadores dos vírus das hepatites $\mathrm{B}$ e delta, uma alta prevalência da infecção pelo HBV (anti-HBc: $85,5 \%$ e anti-HBs: $18 \%$ ) e um elevado número de portadores do mesmo vírus (HBsAg: $11,6 \%)$. Dos soros positivos para o HBsAg (8/69), examinados para detecção do anti-Delta, apenas um mostrou-se negativo (Bensabath $G$ : dados não publicados). Isso indica que quase todos os portadores do vírus da hepatite $\mathrm{B}$ já haviam sofrido uma superinfecção pelo delta. De um dos meninos falecidos, aquelo de cujo sangue se isolou o vírus da febre amarela, o resultado da pesquisa para os marcadores, entretanto, deu o seguinte resultado: HBsAg - neg.; anti-HBc -posit. e anti-HBs - posit.

Apesar da intensa degeneração gorda multivacuolar presente nos hepatócitos da menina do caso em questão, observou-se, a um exame mais acurado, que a lesão era nitidamente mediozonal os hepatócitos em torno das veias centrolobulares e das áreas portais estavam em grande parte conservados -, e que corpúsculos hialinos, embora raros, apareciam entre as células em "mórula". Finalmente, a existência de antígeno do vírus da febre amarela, nos cortes histológicos, confirmou o diagnóstico.

Queremos destacar a importância da demonstração do antígeno amarílico, em cortes de tecidos formolizados do fígado ${ }^{2}$, quando se tratar de casos suspeitos, porém com alteracões microscópicas não características. A lesão de Rocha Lima nem sempre exibe o aspecto salpicado clássico, onde predomina a necrose hialina dos hepatócitos. Em ocasiões, como no caso da criança Yanomami ora comentado, os corpúsculos de Councilman são raros, predominando na alteracão mediozonal a degeneração gorda multivacuolar dos hepatócitos. $\mathrm{Na}$ verdade, as proporcões dos dois componentes principais da lesão - necrose hialina (levando à formação dos corpúsculos de Councilman) e esteatose multivacuolar - podem variar bastante; nos extremos ocorreria, então, uma predominância quase absoluta da necrose hialina ou da degeneração gorda multivacuolar. No caso de preponderar a esteatose, o quadro resultante é capaz de suscitar dúvidas.

\section{REFERÊNCIAS BIBLIOGRÁFICAS}

1. Dias LB, Moraes MAP. Hepatite de Lábrea. Revista do Instituto de Medicina Tropical de São Paulo 15:86-93, 1973

2. Hall WC, Crowell TP, Watts DM, Barros VLR, Kruger H, Pinheiro F, Peters CJ. Demonstration of yellow fever and dengue antigens in formalin-fixed paraffm-embedded human liver by immunohistochemical analysis. The American Journal of Tropical Medicine and Hygiene 45:408-417, 1991. 